\title{
PENGGUNAAN SOFTWARE OPTIMASI PENCAHAYAAN SEBAGAI MEDIA PEMBELAJARAN MATA KULIAH FISIKA BANGUNAN
}

\author{
Erna Kusuma Wati \\ Program Studi Teknik Fisika, Universitas Nasional \\ Email:ernakusuma.w@gmail.com
}

\begin{abstract}
Abstrak
Penelitian ini bertujuan untuk menggunakan media pembelajaran pada Mata Kuliah Fisika Bangunan dengan software DIALux guna membantu mahasiswa memahami konsep intensitas pencahayaan. Penelitian ini dilakukan dengan menggunakan bentuk pembelajaran SCL dan based on problem. Mahasiswa melakukan pengukuran iluminasi cahaya dengan menggunakan luxmeter di Laboratorium Mikrobiologi dan Genetika Universitas Nasional, berdasarkan hasil pengukuran nilai iluminasi tidak sesuai dengan standard. Masing-masing kelompok mahasiswa bertugas untuk melakukan optimasi pencahayaan ruangan laboratorium tersebut dengan menggunakan software DIALux agar sesuai standard SNI yaitu 500lux. Optimasi terhadap pencahayaan dengan menggunakan software DIALux yang dilakukan oleh masing-masing kelompok mahasiswa mampu mencapai nilai standard. Pembelajaran dengan menggunakan media software DIALux pada mata kuliah Fisika Bangunan dapat membantu mahasiswa lebih aktif karena terlibat secara langsung dalam problem solving, sehingga mampu menambah pemahaman konsep terhadap pencahayaan.
\end{abstract}

Kata Kunci : Media Pembelajaran, Optimasi Pencahayaan, SCL

\section{Abstract}

This research aims to use learning media in Building Physics Subjects with DIALux software to help students understand the concept of lighting intensity. This research was conducted using SCL learning and based on problems. Students took measurements of illumination using a luxmeter at the Microbiology and Genetics Laboratory of the National University, based on the results, the illumination measurements value was not in accordance with the standard. Each group was assigned to optimize the lighting in the laboratory using DIALux software to conform to SNI standards that was 500lux. Optimization of light using DIALux software carried out by each student group was able to reach a standard value. Learning by using DIALux software media in the Building Physics course can help students be more active because they are directly involved in problem-solving so that they can increase their understanding of the concept of lighting.

Key Words : Learning Media, Lighting Optimization, SCL

\section{PENDAHULUAN}

Untuk meningkatkan pemahaman konsep materi terhadap mahasiswa, metode pembelajaran Teacher Centered Learning pada perguruan tinggi sudah tidak dapat diterapkan lagi [1]. Metode TCL membuat mahasiswa pasif karena pembelajaran hanya terpusat kepada dosen [2]. Oleh karena itu, perlu mengubah paradigma bahwa proses pembelajaran harus melibatkan keaktifan mahasiswa, dengan demikian mahasiswa mampu meningkatkan pemahaman dan konsep dari materi yang disampaikan. Metode pembelajaran Student Centered Learning merupakan metode pembelajaran yang menempatkan mahasiswa sebagai pusat pada suatu proses pembelajaran, sehingga metode SCL mampu mendorong dan memotivasi mahasiswa untuk berpartisipasi secara aktif, memiliki daya kritis, mampu menganalisa dan dapat memecahkan permasalahan [2].

Program Studi Teknik Fisika, Universitas Nasional memiliki lima bidang peminatan yaitu rekayasa instrumentasi dan kontrol, rekayasa material, rekayasa energi, rekayasa akustik, dan rekayasa fotonika. Fisika bangunan merupakan salah satu 
mata kuliah wajib untuk bidang rekayasa energi. Fisika Bangunan mempelajari mengenai bangunan, pencahayaan, akustik, thermal, dan energi [2]. Oleh karena itu, pada MK tersebut perlu menerapkan metode pembelajaran dengan menggunakan SCL, melibatkan keaktifan mahasiswa dalam proses belajar merupakan hal yang penting guna memahami konsep materi.

Pada penelitian ini, akan menerapkan metode pembelajaran SCL guna mendorong aktivitas mahasiswa pada proses pembelajaran. Materi yang akan digunakan dalam penelitian ini adalah mengenai pencahayaan. Dengan memberikan permasalahan terhadap pencahayaan, mahasiswa diharapkan mampu melakukan optimasi pencahayaan agar sesuai dengan Standard SNI. Dalam pembelajaran ini menggunakan media peraga berbasis simulasi computer yaitu dengan simulasi DIALux. Penggunaan software dalam pembelajaran ini diharapkan menjadi sarana untuk mempertajam pemahaman optimasi cahaya dilakukan secara nyata dan langsung [3]. DIALux merupakan software simulasi pencahayaan, untuk indoor maupun outdoor, serta mengenai pencahyaan alami dan buatan. Fungsi dari DIAlux yaitu untuk membangun suatu optimasi pencahayaan dengan menampilkan pemodelan 3D, memprediksi cahaya, dan memberikan perhitungan parameter obyektif dari skenario tersebut [4]. Program DIALux ini digunakan untuk melakukan proses verifikasi terhadap hasil pengukuran besaran luminasi di lapangan dan simulasi optimasi dengan berbagai macam eksperimen desain pencahayaan menggunakan material library yang telah disediakan di dalam program tersebut [5].

\section{METODE}

Penelitian ini dilakukan pada MK Fisika Bangunan untuk Mahasiswa Angkatan
2017/2018. Metode pembelajaran yang digunakan adalah SCL (Student Centered Learning) based on problem. Kegiatan pembelajaran dilakukan di Laboratorium mikrobiologi dan genetika Universitas Nasional.

Mahasiswa secara berkelompok melakukan pengukuran Iluminasi pencahayaan di ruangan tersebut dengan menggunakan Lux Meter, laser distance meter, meteran. Setelah mengetahui nilai illuminasi maka masing-masing kelompok akan mengetahui hasil pencahayaan yang terukur apakah sudah sesuai dengan standard SNI yaitu sebesar 500 Lux [6], jika belum sesuai maka masing-masing kelompok bertugas untuk melakukan optimasi pencahayaan agar sesuai dengan standard dengan menggunakan media pembelajaran Software DIALux.

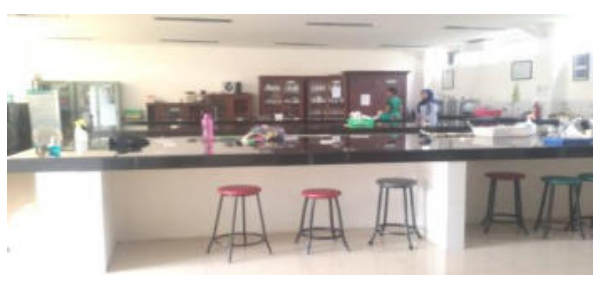

\section{Gambar 1. Laboratorium Mikrobiologi dan Genetika Universitas Nasional}

Untuk melakukan pengukuran pada ruangan tersebut yaitu dengan menggunakan metode sebagai berikut.

1. Luas ruangan $<10 \mathrm{~m}^{2}$

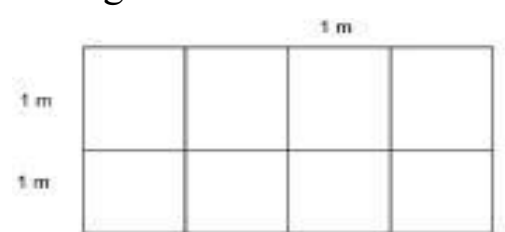

Gambar 2. Penentuan Titik [6]

2. Luas ruangan antara 10 meter persegi sampai 100 meter persegi

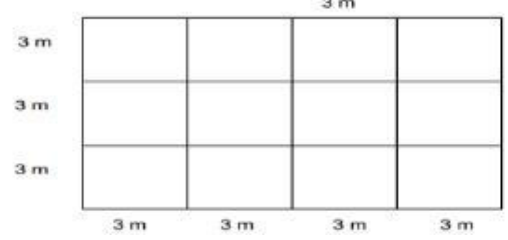

Gambar 3. Penentuan Titik [7] 
3. Luas ruangan lebih dari 100 meter persegi.

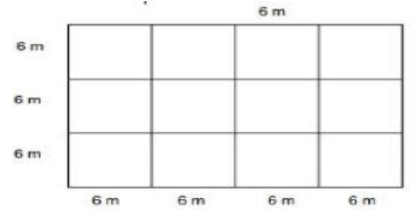

Gambar 4. Penentuan Titik [8]

Pada Gambar 5 merupakan titik yang akan diambil pada pengukuran di labroatorium mikrobiologi dan genetika Universitas Nasional T1, T2 T3, dan T4 merupakan pengambilan data berdasarkan ruangan, sedangkan untuk no. $12,3,4,5,6,7,8$, dan 9 merupakan pengambilan data pada meja kerja.

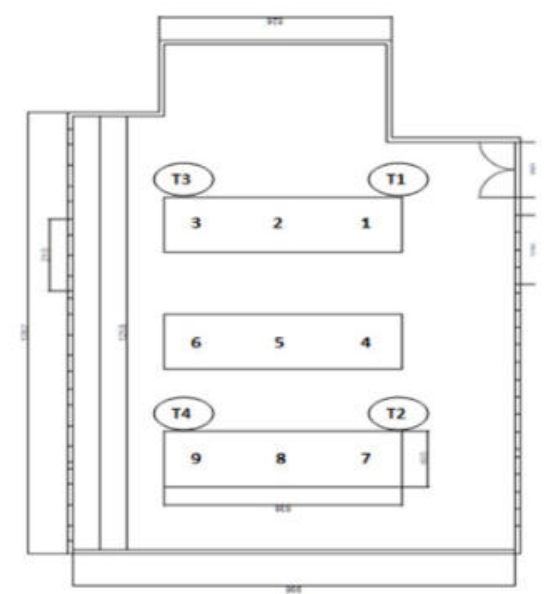

\section{Gambar 5. Penentuan Titik Pengukuran}

\section{HASIL DAN PEMBAHASAN}

Pada metode pembelajaran SCL based on problem, mahasiswa menjadi terlibat secara langsung, dalam proses pengukuran iluminasi, mereka secara langsung mengetahui masalah yang ada di ruangan tersebut, kemudian mereka berusaha untuk memecahkan dan menyelesaikan pencahayaan agar sesuai dengan standard [9]. Guna melibatkan mahasiswa untuk bersikap aktif, dan mampu berpikir untuk menemukan masalah dan memecahkannya [10], maka perlu melibatkan mahasiswa secara langsung dalam pengukuran iluminasi cahaya menggunakan alat luxmeter diletakkan di titik-titik yang sudah ditentukan dengan meletakkan di atas bidang kerja yaitu pada ketinggian 0,75 meter dari permukaan lantai, yang pada dasarnya titik-titik tersebut menjadi pusat efektivitas para mahasiswa untuk melakukan praktikum. Pada penelitian ini akan diambil data tingkat pencahayaan dalam 4 waktu untuk mewakili kondisi pencahayaan alami dan buatan yaitu:

1) Pukul 09.00 WIB

2) Pukul $12.00 \mathrm{WIB}$

3) Pukul 15.00 WIB

4) Pukul $18.00 \mathrm{WIB}$

Tabel 1. Data Hasil Rata-rata Pengukuran Selama 3 hari

\begin{tabular}{ccccc}
\hline Titik & \multicolumn{4}{c}{ Data Iluminasi (lux) } \\
Pengukuran & Jam & Jam & Jam & Jam \\
& 08.00 & 12.00 & 15.00 & 18.00 \\
\hline T1 & 1885 & 2186 & 1985 & 1783 \\
T2 & 1869 & 2185 & 1958 & 1729 \\
T3 & 1755 & 2165 & 1824 & 1793 \\
T4 & 1748 & 2071 & 1802 & 1723 \\
1 & 1781 & 2382 & 1984 & 1893 \\
2 & 1590 & 1925 & 1807 & 1764 \\
3 & 1563 & 2194 & 1835 & 1809 \\
4 & 1775 & 2367 & 1933 & 1858 \\
5 & 1579 & 1894 & 1835 & 1806 \\
6 & 1560 & 2147 & 1835 & 1820 \\
7 & 1770 & 2205 & 1973 & 1835 \\
8 & 1570 & 1814 & 1821 & 1764 \\
9 & 1421 & 2136 & 1855 & 1823 \\
Rata-Rata & & & & \\
& 1682 & 2128 & 1880 & 1800
\end{tabular}

Nilai pengukuran iluminasi pada pukul 09.00 WIB, 12.00 WIB, 15.00 WIB, dan 18.00 WIB melebihi dari standard. Hal ini disebabkan laboratorium menghadap ke timur, sehingga banyak cahaya alami yang masuk ke dalam. Jika cahaya yang masuk ke dalam laboratorium berlebih dapat menyebabkan silau saat mahasiswa sedang melakukan praktikum, selain itu juga dapat menyebabkan bayangan di sekitar meja kerja. Oleh karena itu, hal ini perlu diperhatikan karena Laboratorium Mikrobiologi dan Genetika juga dipakai mahasiswa melakukan penelitian, jika 
pencahayaan di laboratorium tersebut tidak sesuai standard maka dapat mempengaruhi hasil penelitian lainnya.

\section{Perancangan dan Simulasi}

Tahapan pertama yaitu mahasiswa melakukan perancangan dengan membuat permodelan ruang dalam software [11] yang kondisinya dibuat semirip mungkin dengan kondisi lapangan (verifikasi) dengan tidak mengubah jenis \& jumlah luminaire. Tahapan kedua yaitu dilakukan optimasi dengan cara mengganti jenis dan jumlah luminaire agar mencapai kondisi pencahayaan laboratorium yang ideal. Waktu yang ditampilkan pada simulasi disesuaikan dengan waktu saat pengambilan data menggunakan alat luxmeter yaitu pada pukul 09.00, 12.00, 15.00, dan 18.00 saat kondisi cahaya di laboratorium cerah. False color display yaitu penyebaran tingkat iluminasi penerangan dengan visualisasi melalui tampilan warna-warna yang berbeda yang disesuaikan dengan besar tinggi iluminasi penyebaran cahayanya. Isoline rendering pada DIALux menunjukkan potongan garis pada ruangan dengan menampilkan nilai lux. Berikut ini akan dijelaskan hasil simulasi DIALux.

\section{Hasil DIAlux Pukul 09.00 WIB}

Nilai iluminasi pada pengukuran sudah terlalu tinggi dan tidak merata. Pada Gambar 6, menunjukkan hasil rendering false color. Tampilan false colour rendering pada pukul 09.00 didominasi dengan warna abu-abu, warna ini tidak terdapat pada rentang yang mengartikan nilai iluminasi nya lebih dari 500 lux.

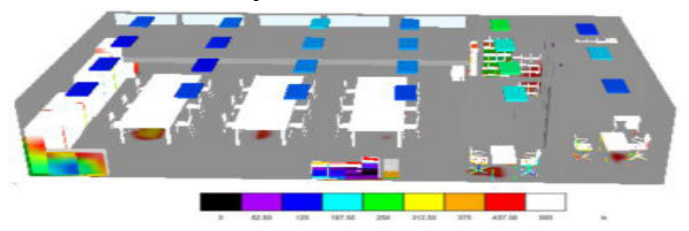

Gambar 6. False Color Rendering Kondisi Verifikasi Pukul 09.00 WIB
Hasil kontur cahaya ini menjelaskan bahwa iluminasi rata-rata di area workplace $\left(\mathrm{E}_{\mathrm{av}}\right) 1835$ lux, minimal $\left(\mathrm{E}_{\mathrm{min}}\right)$ 52 lux dan maksimal $\left(\mathrm{E}_{\max }\right) 2853$ lux, sedangkan pada pengukuran menggunakan luxmeter angka yang terbaca rata-rata (Eav) 1682 lux. Selanjutnya Simulasi pencahayaan kedua untuk optimasi dilakukan dengan mengganti jenis dan jumlah armatur agar pencahayaan di laboratorium mencapai kondisi sesuai dengan standard. Hasil False color rendering menunjukkan iluminasi di meja kerja sudah sesuai yaitu 500 lux yang di tampilkan dengan warna putih seperti pada Gambar 7 berikut ini.

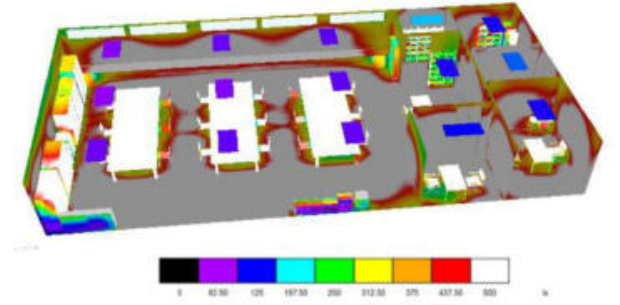

Gambar 7. False Color Rendering Kondisi Optimasi Pukul 09.00 WIB

Hasil kontur cahaya pada Gambar 7 menjelaskan bahwa iluminasi rata-rata di area workplace $\left(\mathrm{E}_{\mathrm{av}}\right) 535$ lux, minimal (Emin) 14 lux dan maksimal $\left(E_{\max }\right) 1368$ lux. Walaupun yang ditunjukkan pada gambar di meja kerja menunjukkan 250 lux itu dikarenakan penunjukan angkanya berdekatan. Namun untuk di meja kerja iluminasi yang diperoleh 500 lux.

\section{Hasil DIALux Pukul 12.00 WIB}

Hasil simulasi false color rendering Gambar 8 pada pukul 12.00 menunjukkan di sekitar meja kerja pencahayaannya sangat terang karena jendela pada laboratorium berada di sisi sebelah timur, sehingga banyak tambahan cahaya alami yang masuk ke dalam laboratorium. Selain itu, semua lampu yang ada pada ruang praktikum dalam kondisi menyala karena pada jam tersebut mahasiswa sedang praktikum. 


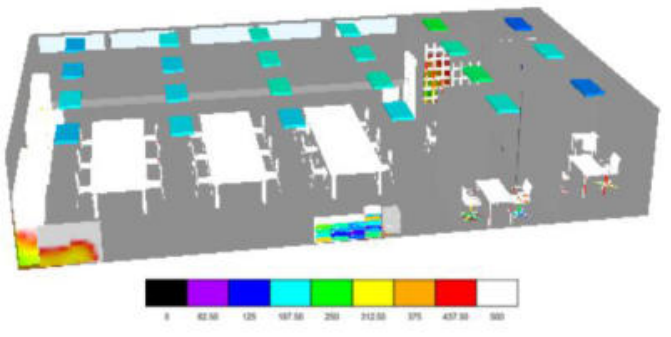

Gambar 8. False Color Rendering Kondisi Verifikasi Pukul 12.00 WIB

Gambar 8 merepresentasikan hasil perhitungan atau kalkulasi desain pencahayaan. Pada gambar terlihat bahwa pencahayaan di laboratorium belum merata karena nilai iluminasi dekat bukaan jendela sangat besar yaitu iluminasi rata-rata di area workplace $\left(\mathrm{E}_{\mathrm{av}}\right) 2118$ lux, minimal $\left(E_{\min }\right) 59$ lux dan maksimal $\left(\mathrm{E}_{\max }\right) 4033$ lux, sedangkan pada pengukuran menggunakan luxmeter angka yang terbaca rata-rata $\left(E_{a v}\right) 2128$ lux. Nilai iluminasi pada Gambar 9 yang merupakan hasil optimasi, menunjukkan pada meja kerja sudah mencapai 500 lux. Namun untuk iluminasi sekitar meja kerja nilai iluminasinya masih tinggi karena sumber cahaya alami tidak terhalang, dan jendela menggunakan kaca bening sehingga cahaya dapat menembus sempurna.

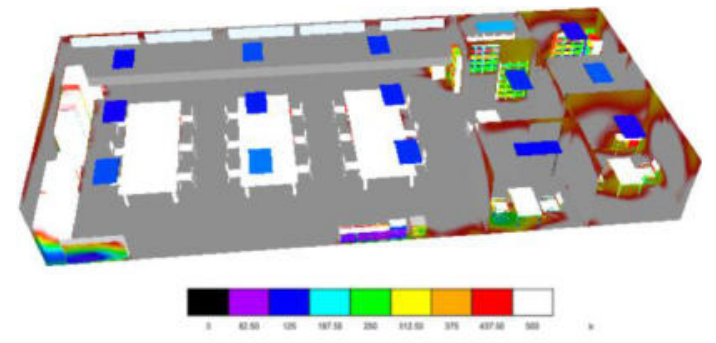

Gambar 9. False Color Rendering Kondisi Optimasi Pukul 12.00 WIB

\section{Hasil DIALux Pukul 15.00 WIB}

Dari hasil false colour rendering seperti pada Gambar 10 dapat dilihat bahwa pada pukul 15.00 WIB untuk keseluruhan laboratorium masih terlalu terang jika menggunakan lampu yang digunakan saat ini. Oleh karena itu, perlu dilakukan simulasi dengan mengganti jenis dan jumlah luminaire.

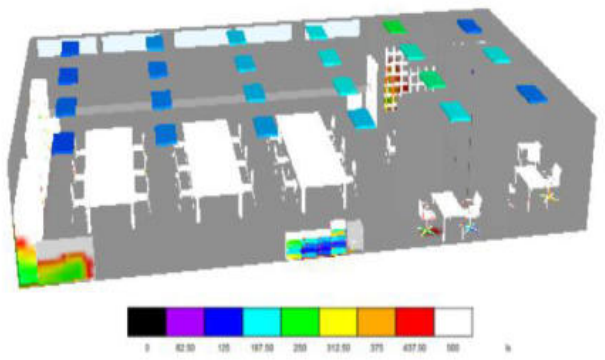

\section{Gambar 10. False Color Rendering Kondisi Verifikasi Pukul 15.00 WIB}

Pada gambar 10 memperlihatkan hasil kontur cahaya ini menjelaskan bahwa iluminasi rata-rata di area workplace $\left(\mathrm{E}_{\mathrm{av}}\right)$ 1960 lux, minimal $\left(E_{\min }\right) 54$ lux dan maksimal $\left(E_{\max }\right) 3252$ lux. Sedangkan pada pengukuran menggunakan luxmeter nilai iluminasi rata-rata $\left(\mathrm{E}_{\mathrm{av}}\right) 1880$ lux, sehingga hasil simulasi kondisi aktual dengan pengukuran langsung sudah mendekati. Nilai iluminasi pada meja kerja sudah mencapai 500 lux. Untuk daerah yang mendapatkan pencahayaan maksimal yaitu pada sisi bagian timur dan barat karena dekat dengan bukaan jendela.

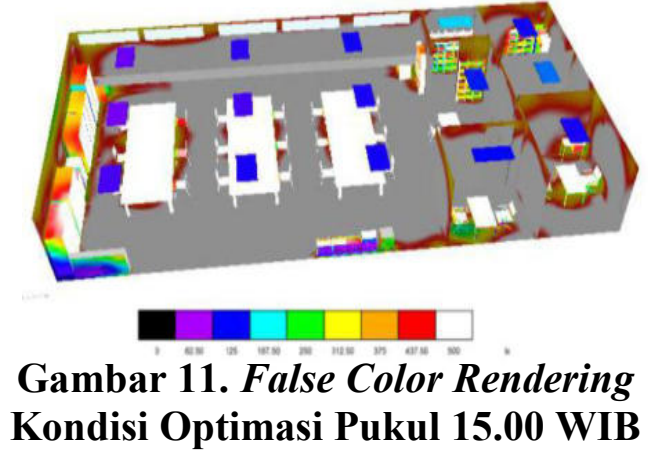

Hasil kontur cahaya pada Gambar 11 menjelaskan bahwa iluminasi rata-rata di area workplace $\left(\mathrm{E}_{\mathrm{av}}\right) 448$ lux, minimal $\left(E_{\min }\right) 190$ lux dan maksimal $\left(E_{\max }\right) 1026$ lux. Nilai tersebut merupakan rata-rata ruang laboratorium, untuk nilai iluminasi di meja kerja dapat melakukan controling lampu yaitu memilih lampu mana saja yang hidup. 


\section{Hasil DIALux Pukul 18.00 WIB}

Dari hasil false colour rendering masih tidak sesuai standar karena pada saat cahaya alami yang masuk tidak banyak dan semua lampu menyala tetap masih sangat melebihi standar untuk pencahayaan di ruang praktikum, sehingga perlu dilakukan simulasi dengan mengganti jenis dan jumlah luminaire nya.

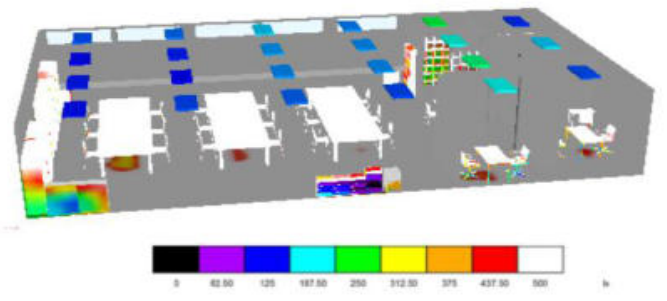

\section{Gambar 12 . False Color Rendering} Kondisi Verifikasi Pukul 18.00 WIB

Pada Gambar 12 menunjukkan kontur cahaya dari hasil perhitungan dan permodelan 3D DIALux 4.13 dengan nilai iluminasi rata-rata di area workplace $\left(\mathrm{E}_{\mathrm{av}}\right)$ 1711 lux, minimal $\left(\mathrm{E}_{\min }\right) 47$ lux dan maksimal ( $\left.E_{\max }\right) 2752$ lux, sedangkan pada pengukuran menggunakan luxmeter nilai iluminasi rata-rata $\left(\mathrm{E}_{\mathrm{av}}\right)$ yaitu 1800 lux sehingga hasil simulasi kondisi aktual dengan pengukuran langsung sudah mendekati.

Hasil rendering false color pada Gambar 13 nilai iluminasi pada meja kerja sudah mencapai 500 lux terlihat pada false color menampilkan warna putih.

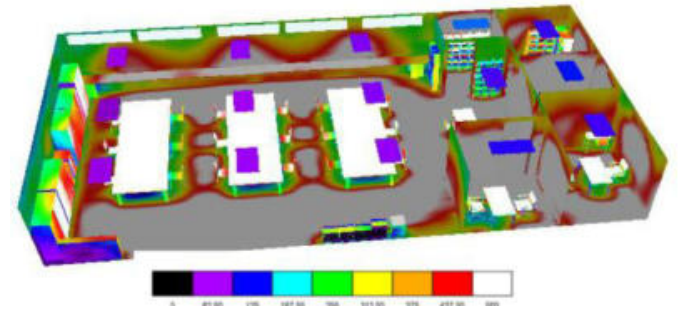

\section{Gambar 13. False Color Rendering Kondisi Optimasi Pukul 18.00}

Hasil kontur cahaya pada Gambar 13 menjelaskan bahwa iluminasi rata-rata di area workplace $\left(\mathrm{E}_{\mathrm{av}}\right) 574$ lux, minimal $\left(E_{\min }\right) 15$ lux dan maksimal $\left(E_{\max }\right) 1205$ lux. Pukul 18.00 merupakan waktu yang baik untuk melakukan pengecekan lampu yang digunakan untuk optimasi sudah sesuai atau belum untuk mencapai nilai idel pencahayaan laboratorium. Karena pada pukul 18.00 cahaya alami dari matahari sudah tidak ada hanya cahaya buatan dari lampu.

Dengan melakukan beberapa simulasi untuk mencapai nilai standard [8] mahasiswa mampu berpikir dan memberikan alasan dalam memberikan rekomendasi pemecahan masalah pencahayaan. Kemampuan berpikir serta pemahaman konsep mahasiswa dalam pengukuran secara langsung di lapangan yang diharapkan mampu membuat perubahan dalam proses pembelajaran, yang tidak hanya mengacu/ berpusat pada dosen [11].

\section{SIMPULAN}

Berdasarkan hasil penelitian, maka dapat disimpulkan bahwa: (1) Ruang praktikum Laboratorium Mikrobiologi dan Genetika Universitas Nasional memiliki nilai iluminasi rata-rata pada pukul 09.00 yaitu 1682 lux, pukul 12.00 sebesar 2128 lux, pukul 15.00 sebesar 1880 lux, dan pada pukul 18.00 sebesar 1800 lux. Nilai iluminasi tersebut menunjukkan pencahayaan di ruang praktikum laboratorium sangat terang. Oleh karena itu, perlu dilakukan optimasi pencahayaan dengan mengganti jenis dan jumlah luminaire. (2) Untuk melakukan Optimasi pencahayaan yang dilakukan pada Laboratorium Mikrobiologi dan Genetika yaitu dengan mengganti menjadi 9 armatur dan jenis luminaire yang digunakan RM 4xMASTER TLED 18W/865 P. Dari hasil simulasi optimasi didapat nilai iluminasi rata-rata pada pukul 09.00 yaitu 535 lux, pukul 12.00 sebesar 662 lux, pukul 15.00 sebesar 448 lux, dan pukul 18.00 nilai 
iluminasi 574 lux. Kondisi optimasi pencahayaan yang telah dibuat dapat dijadikan pertimbangan untuk perancangan sistem pencahayaan ruang praktikum laboratorium yang telah memenuhi standar SNI. (3) Metode pembelajaran SCL based on problem mampu melibatkan mahasiswa secara aktif dalam proses pembelajaran, dan mahasiswa memahami konsep materi dengan menyelesaikan permasalahan yang ada. (4) Pembelajaran dengan menggunakan software optimasi 3D DiaLux dapat dijadikan referensi untuk media pembelajaran pada materi pencahayan alami dan buatan.

\section{DAFTAR PUSTAKA}

[1] R. R. Antika. "Proses Pembelajaran Berbasis Student Centered Learning (Studi Deskriptif di Sekolah Menengah Pertama Islam Baitul 'Izzah, Nganjuk)". Jurnal BioKultur, Vol. III, No. 1, pp. 251, 2014.

[2] A. Ardian dan S. Munadi. "Pengaruh Strategi Pembelajaran StudentCentered Learning dan Kemampuan Spasial terhadap Kreativitas Mahasiswa". Jurnal Pendidikan Teknologi dan Kejuruan, Vol. 22, No. 4, pp. 454, 2015.

[3] A. Suhandi, P. Sinaga, I. Kaniawati, E. Suhendi. "Efektivitas Penggunaan Media Simulasi Virtual pada Pendekatan Pembelajaran Konseptual Interaktif dalam Meningkatkan Pemahaman Konsep dan Meminimalkan Miskonsepsi”. Jurnal Pengajaran MIPA, Vol. 7,
No. 13, pp 35-48, 2009

[4] T. Handayani. "Efisiensi Energi dalam Rancangan Bangunan". Jurnal spectrum sipil, Vol. 1, No. 2, pp. 102 - 108, 2014.

[5] N. Madarina dan W. A. Asmoro, "Perancangan Pencahayaan GOR Target Menerapkan Konsep Green Building". Jurnal Teknik Pomits. Vol 2, No. 2, 2013.

[6] M. Hesson and K. F. Shad. A Student Centered Learning Model. American Journal of Applied Sciences, Vol. 4, No.9, pp. 628-636, 2007.

[7] Badan Standarisasi Nasional. SNI 03-6575-2001 tentang Tata Cara Perancangan Sistem Pencahayaan Buatan. Bandung: Badan Standarisasi Nasional, 2001.

[8] Badan Standarisasi Nasional. SNI 032396-2001 tentang Tata Cara Perancangan Sistem Pencahayaan Alami. Bandung: Badan Standarisasi Nasional, 2001.

[9] Badan Standarisasi Nasional. SNI 16-7062-2004 tentang Pengukuran Intensitas Penerangan di Tempat Kerja. Bandung: Badan Standarisasi Nasional, 2004.

[10] K. J. Holyoak \& R. G. Morrison. The Cambridge Handbook of Thinking and Reasoning. New York: Cambridge University Press, 2005.

[11] R. Hadi. "Perubahan Metode Pembelajaran di Perguruan Tinggi". Jurnal Pemikiran Alternatif Pendidikan INSANIA, Vol. 12, No. 3, 408-419. 2007. 